\title{
Treatment of Craniomaxillofacial Fibrous Dysplasia
}

\author{
Takayuki Okumoto', Masaki Yazawa2*, Yoshikazu Inoue1, Kazuo Kishi² \\ ${ }^{1}$ Plastic and Reconstructive Surgery, Fujita Health University Hospital, \\ Toyoake, Japan \\ ${ }^{2}$ Plastic and Reconstructive Surgery, Keio University School of Medicine, \\ Tokyo, Japan \\ Email: *prsyazawa@gmail.com
}

Received 13 May 2015; accepted 6 June 2015; published 9 June 2015

Copyright (C) 2015 by authors and Scientific Research Publishing Inc.

This work is licensed under the Creative Commons Attribution International License (CC BY). http://creativecommons.org/licenses/by/4.0/

(c) (i) Open Access

\section{Abstract}

Fibrous dysplasia is a benign osseous disease, although radical resection is commonly recommended because of the possibility of recurrence or malignant change. However, radical resection is undesirable, particularly in the maxillofacial region, because facial bones are difficult to replace in an aesthetically-pleasing manner after radical excision. In our department, conservative shaving, as reported by Chen and Noordhoff, is used to reduce tumor volume while maintaining facial aesthetics that are as normal as possible. We have experienced eight cases of craniomaxillofacial fibrous dysplasia and successfully applied conservative shaving to the maxillofacial lesions. These cases have exhibited no recurrence, and their facial contours have improved remarkably.

\section{Keywords}

Fibrous Dysplasia, Osseous Disease

\section{Introduction}

Fibrous dysplasia was first reported by Bauer et al. as osteitis fibrosa in 1930 [1] [2], and craniomaxillofacial (CMF) fibrous dysplasia was first reported in 1956 [3]. Fibrous dysplasia is a benign osseous disease, which is defined as a tumor-like osseous lesion in which normal bone is replaced by fibro-osseous tissue. Developmental defect of osseous tissue is produced with an abnormally thin cortex and marrow is replaced with fibrous tissue. In previous reports, bisphosphonate treatment did not show clear beneficial effects, so radical resection has been recommended because of the possibility of recurrence or malignant change. However, radical resection is unde-

\footnotetext{
${ }^{*}$ Corresponding author.
} 
sirable, particularly in the maxillofacial region. Therefore, controversy exists regarding whether CMF fibrous dysplasia should be treated with radical excision and reconstruction or partial excision (shaving). In our department, conservative shaving has been selected to reduce tumor volume, thereby maintaining facial aesthetics that are as normal as possible. After confirmation that osseous growth has ceased, our conservative shaving has been successfully applied to the maxillofacial lesions.

\section{Patients and Methods}

In our department, as we agree with Drs. Chen and Noordhoff's concept [4], conservative shaving has been selected as the standard treatment for CMF fibrous dysplasia. In their concept, Drs. Chen and Noordhoff suggested treatment principles that are related to dysplastic zones, which classify four facial zones according to their importance of reconstruction, anatomic location, and treatment procedure (Table 1). Zone 1 is the upper and midfacial area, which is the most prominent facial part. This area can be excised completely and reconstructed adequately; therefore, radical excision and reconstruction are recommended. Zone 2 is the hair-covered area, which is less important than Zone 1; therefore, conservative or radical excision is recommended, if necessary. Zone 3 is the most difficult and dangerous facial area; therefore, observation is recommended, and surgery should be avoided if the patient does not complain of related symptoms. Zone 4 should be treated using partial excision, as this area contains the alveolar region that is involved in mastication.

We have experienced eight cases of CMF fibrous dysplasia (Table 2), including six that were treated by conservative shaving and two that have been observed. Although an optimal time for surgery has not been defined, surgery is performed over approximately 20-year-old when the osseous lesion appeared to have stopped progressing. Our standard treatment procedure is partial excision by shaving, which is indicated when the osseous lesion appears to have stopped progressing, and further progression appears unlikely. Our representative cases are described below.

\subsection{CASE 3}

A 23-year-old woman (Figure 1) presented with swelling of the left buccal region and gingival hypertrophy. She was diagnosed with McCune-Albright syndrome by hyperpigmentation of the skin (café-au-lait spots) and sexual prematurity at the age of 16 years. We performed shaving of the zygomatic and maxillary bones, with an autologous blood transfusion (1200 cc). At the five- and eight-year follow-ups, computed tomography (CT) scanning revealed no recurrence (Figure 2).

Table 1. Treatment principles related to dysplastic zones.

\begin{tabular}{|c|c|c|c|}
\hline & Reconstruction importance & Anatomic location & Treatment procedure \\
\hline \multirow{3}{*}{ Zone 1} & \multirow{3}{*}{ Most evident facial part } & Frontal, orbital, & \\
\hline & & Nasal, ethmoid, & Radical excision and reconstruction \\
\hline & & Zygoma, upper-maxilla & \\
\hline \multirow{4}{*}{ Zone 2} & \multirow{4}{*}{ Hair-covered cranium } & Parietal, & Optional: \\
\hline & & Part of occipital, & Conservative \\
\hline & & Temporal & Or radical \\
\hline & & (Lateral cranial base) & \\
\hline \multirow{3}{*}{ Zone 3} & \multirow{3}{*}{ Difficult or dangerous } & Central cranial base, & Observing: \\
\hline & & Petrous, mastoid, & No surgery when no symptoms \\
\hline & & Pterygoid, sphenoid & \\
\hline Zone 4a & Teeth-bearing & Maxillar alveolar bone & Conservative \\
\hline Zone 4b & Teeth-bearing & Mandible & Conservative \\
\hline
\end{tabular}


Table 2. We have experienced eight cases of craniomaxillofacial fibrous dysplasia, including six that were treated with conservative shaving and two that were observed.

\begin{tabular}{|c|c|c|c|c|c|c|c|c|c|c|}
\hline Case & Sex & Anatomic location & Zone & $\begin{array}{l}\text { 1st visit } \\
\text { age }\end{array}$ & $\begin{array}{l}\text { Observation } \\
\text { term }\end{array}$ & Increase & Operation age & $\begin{array}{l}\text { Treatment } \\
\text { procedure }\end{array}$ & $\begin{array}{l}\text { Postop. } \\
\text { term }\end{array}$ & $\begin{array}{l}\text { Rec. of } \\
\text { tumor }\end{array}$ \\
\hline 1 & $\mathrm{~F}$ & Zygoma & 1 & 45 & $4 \mathrm{M}$ & & 45 & Partial & $19 \mathrm{M}$ & None \\
\hline 2 & $\mathrm{~F}$ & Frontal & 1 & 42 & $1 Y 5 M$ & None & 43 & Partial & $2 \mathrm{Y} \sim$ & None \\
\hline 3 & $\mathrm{~F}$ & $\begin{array}{l}\text { Zygoma sphenoid, temporal, } \\
\text { posterior maxilla mandibula }\end{array}$ & $\begin{array}{c}1 \\
3 \\
4 a \\
4 b\end{array}$ & 23 & $3 \mathrm{M}$ & & 23 & Partial & $8 \mathrm{Y} \sim$ & None \\
\hline 4 & $\mathrm{~F}$ & $\begin{array}{l}\text { Frontal, zygoma sphenoid } \\
\text { Maxilla mandibula }\end{array}$ & $\begin{array}{c}1 \\
3 \\
4 a \\
4 b\end{array}$ & 43 & $4 \mathrm{M}$ & & 44 & Partial & $3 \mathrm{Y} \sim$ & None \\
\hline 5 & M & Maxilla & $1,4 \mathrm{a}$ & 13 & $6 Y$ & None & 19 & Partial & $4 \mathrm{M} \sim$ & Unknown \\
\hline 6 & M & $\begin{array}{l}\text { Frontal, ethmoid } \\
\text { sphenoid }\end{array}$ & $\begin{array}{l}1 \\
3\end{array}$ & 11 & $6 Y$ & None & Inoperable & Observation & & Unknown \\
\hline 7 & $\mathrm{~F}$ & Frontal parietal & $\begin{array}{l}1 \\
2\end{array}$ & 12 & $5 Y$ & None & Inoperable & Observation & & Unknown \\
\hline 8 & $\mathrm{~F}$ & Frontal, ethmoid sphenoid & $\begin{array}{l}1 \\
3\end{array}$ & 10 & $2 \mathrm{Y}$ & + & 12 & $\begin{array}{c}\text { Optic canal } \\
\text { decompression }\end{array}$ & $7 \mathrm{Y}$ & None \\
\hline
\end{tabular}

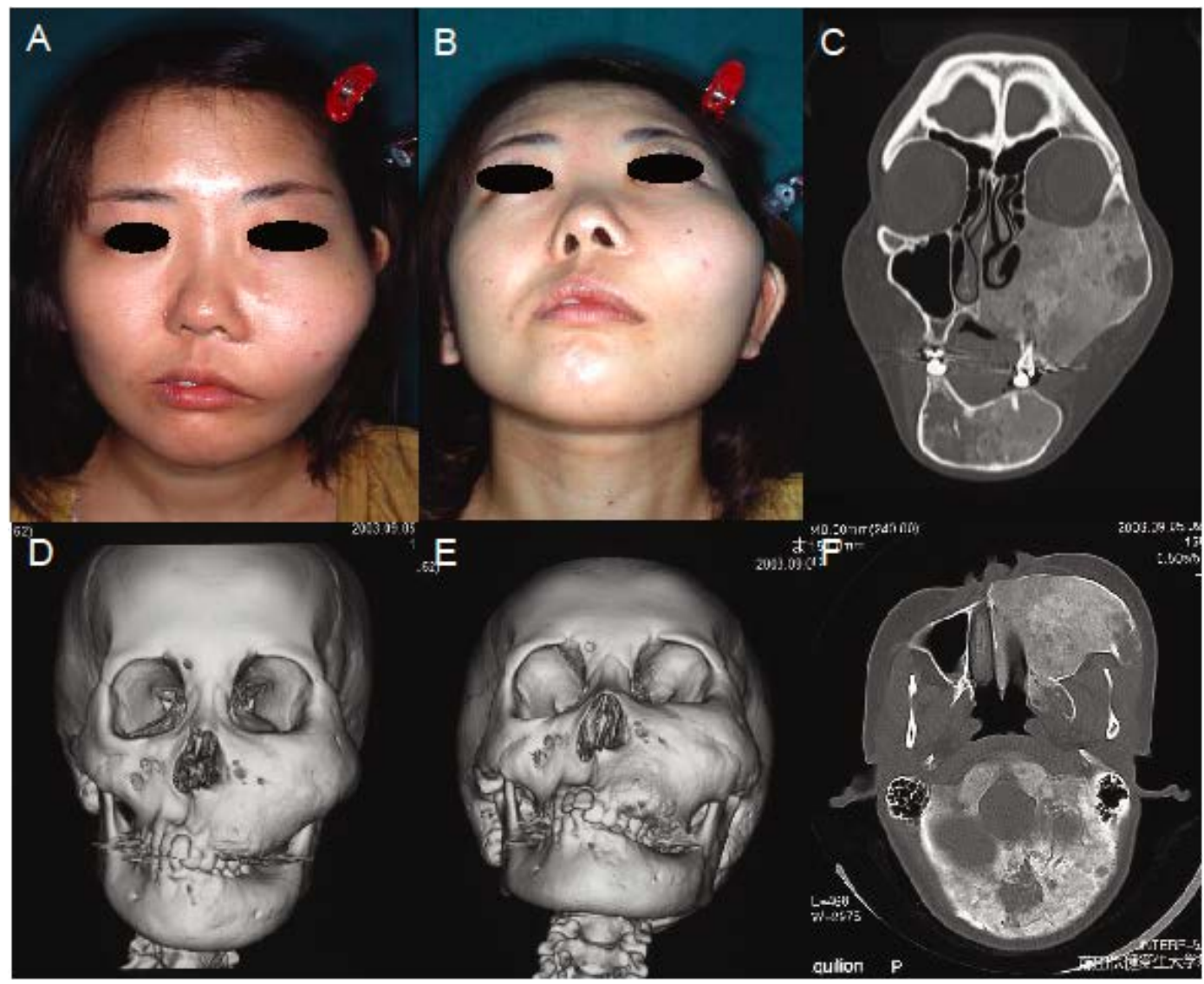

Figure 1. Case 3 preoperative view. A 23-year-old woman was diagnosed with McCune-Albright syndrome by hyperpigmentation of the skin (café-au-lait spots) and sexual prematurity. (A) (B) Appearances, (C)-(F) Computed tomography (CT) scanning.

\subsection{Case 4}

A 43-year-old woman (Figure 3) presented with swelling of the left frontal, zygomatic, maxillary, and mandi- 


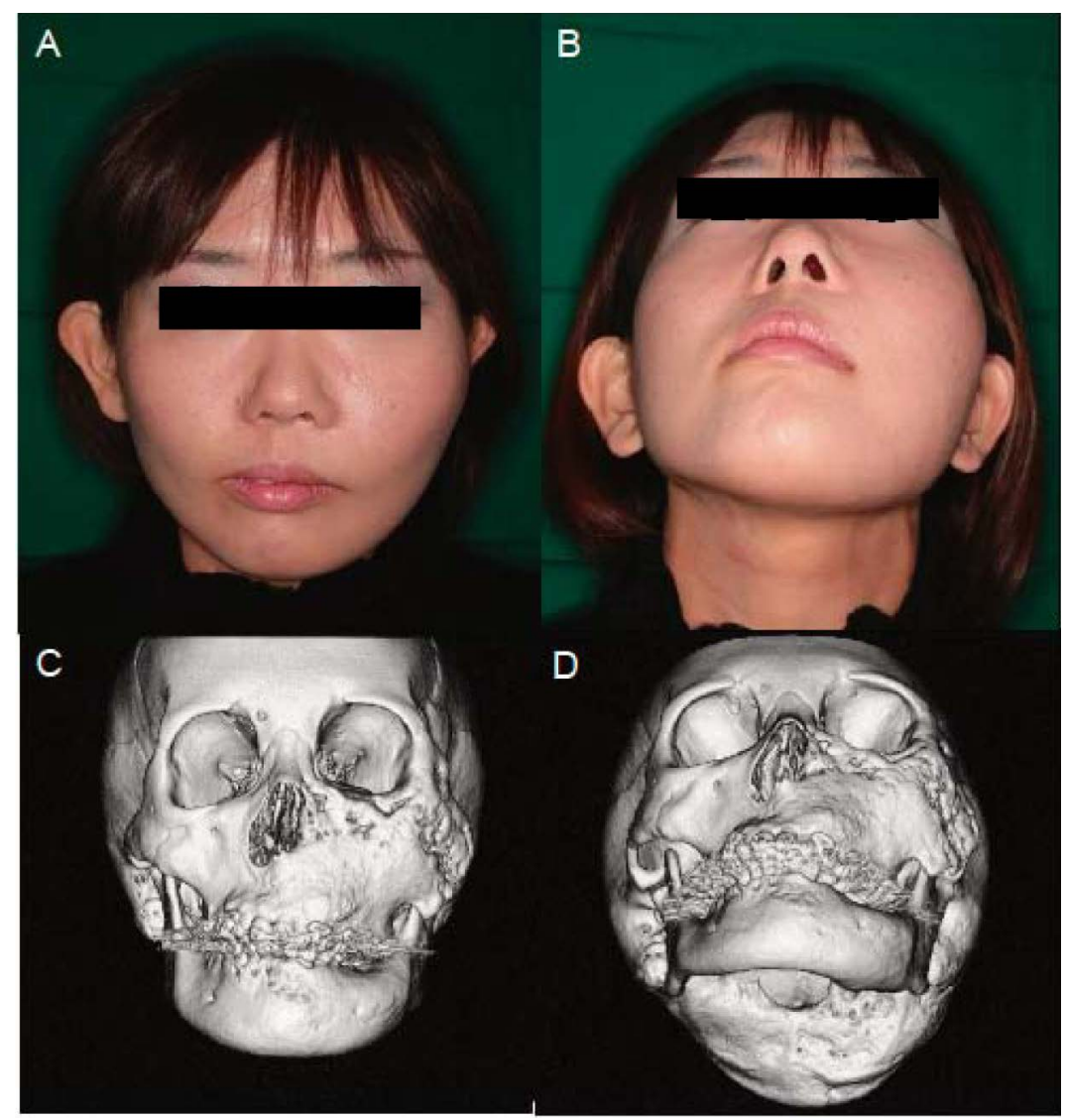

Figure 2. Case 3 postoperative views. Five years after the operation (upper), and 8 years after the operation (lower). (A) (B) Appearances, (C) (D) Computed tomography (CT) scanning.

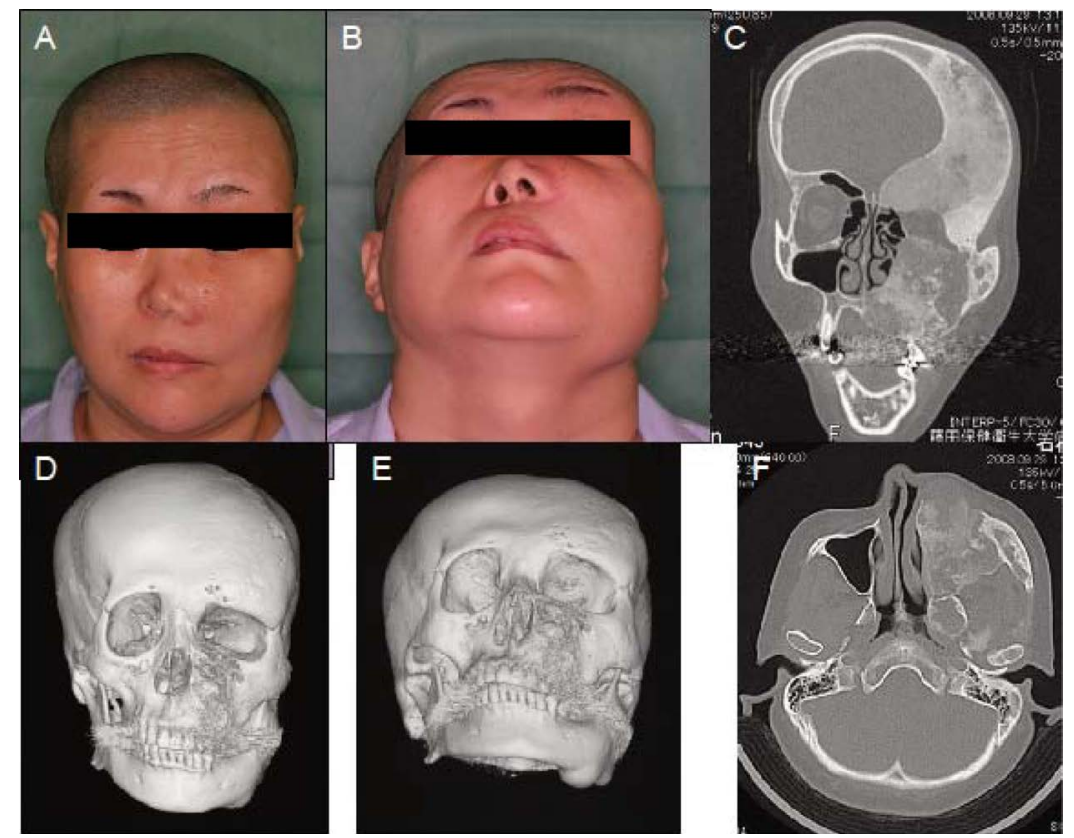

Figure 3. Case 4 preoperative view. A 43-year-old woman with an 18-year-old reduction of maxillary bone that had been performed at another hospital. (A) (B) Appearances, (C)-(F) Computed tomography (CT) scanning. 
bular bones, as well as gingival hypertrophy. Reduction of the maxilla had been performed at another hospital, although osseous hypertrophy remained because of insufficient reduction. Therefore, we performed shaving of the frontal, zygomatic, and maxillary bones. The operative time was one hour, with $423 \mathrm{~g}$ of blood loss and a 1200 cc transfusion of autologous blood. Follow-up CT revealed no recurrence, and the patient has remained healthy (Figure 4).

\subsection{Case 5}

A 19-year-old man (Figure 5) presented with swelling of the left buccal region and gingival hypertrophy. Swelling of the left buccal region began at the age of 5 years. As he experienced no progression over six years of observation, we performed maxilla shaving. The operative time was three hours, with $1086 \mathrm{~g}$ of blood loss and an 800 cc transfusion of autologous blood. However, the follow-up period was only four months after the surgery (Figure 6); therefore, we intend to continue careful observation over a longer period in the future.

\section{Results}

In Cases 1 - 4, the patients had already aged when they presented at our institution; therefore, we performed the shaving operation without long-term observation to evaluate the progression of the lesion. However, in Cases 5 8 , the patients were young when they presented. Thus, we typically only performed the operation after long-term pre-operative observation to confirm that the progression had stopped. In Case 8, the orbital osseous lesion appeared to increase while we were observing. Therefore, optic canal decompression was performed by a neurosurgeon to avoid stenosis-induced vision loss.

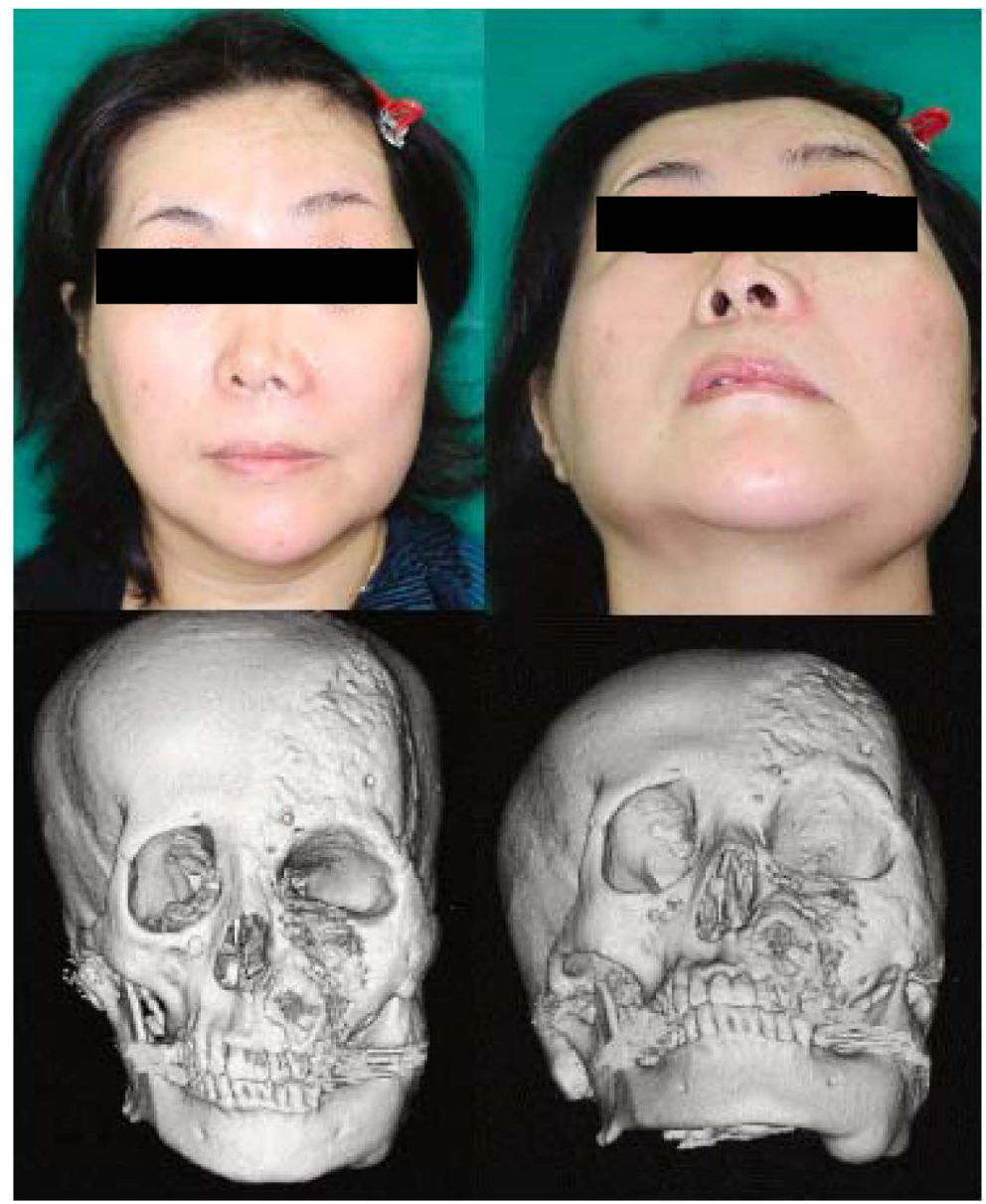

Figure 4. Case 4 postoperative views. Two years and 10 months after the operation (upper), and 2 years and 6 months after the operation (lower). 


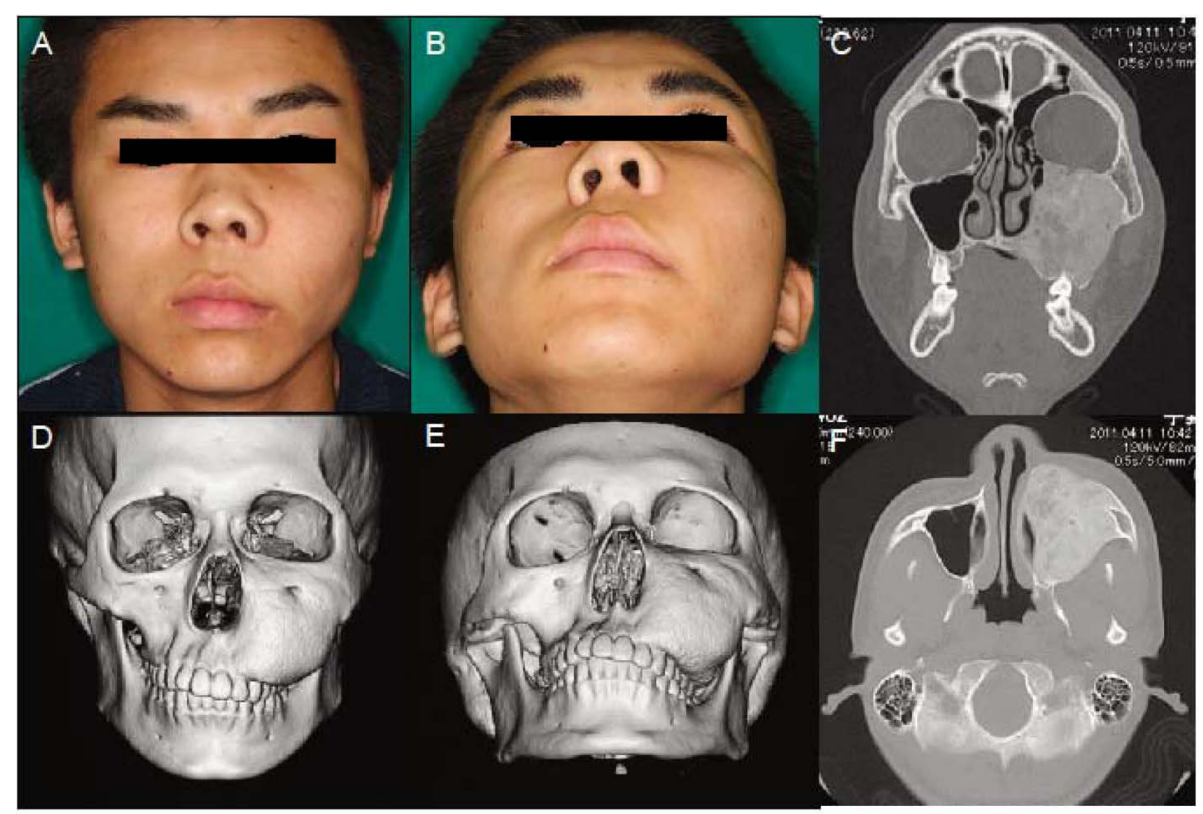

Figure 5. Case 5 preoperative view. A 19-year-old man with no visible increase in the dysplasia with yearly computed tomography scanning. (A) (B) Appearances, (C)-(F) Computed tomography (CT) scanning.

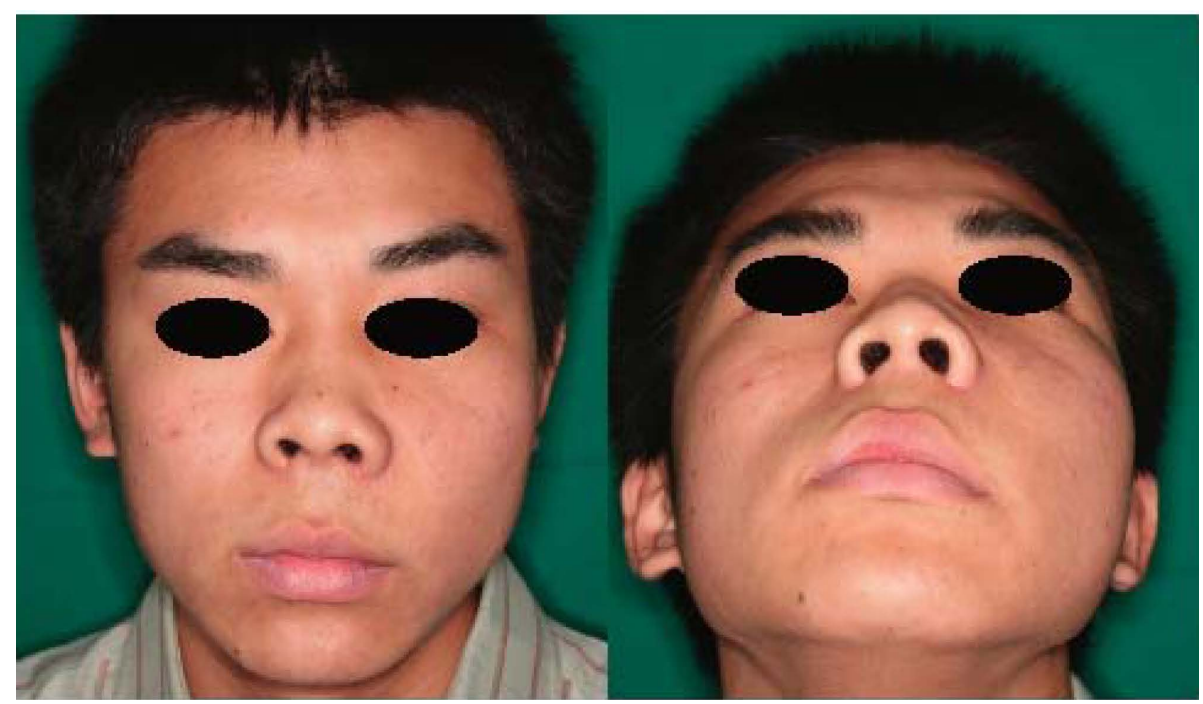

Figure 6. Case 5 postoperative view 4 months after the operation.

We have also conducted long-term post-operative observation in most cases. For example, no recurrence was observed over five years of follow-up in Cases 3 and 8, and no recurrence was observed in the six cases that were treated with conservative shaving. However, the postoperative observation period was not long enough in some cases; therefore, longer observation should be performed in the future. The facial contours in all 8 cases have improved remarkably.

\section{Discussion}

CMF fibrous dysplasia often occurs as the polyostotic type, with more than 50\% onset in CMF region reported in previous studies; our series included five cases of polyostotic dysplasia among the eight cases. The remaining three cases were monostotic, although radical excision would have been difficult as the facial bones were diffi- 
cult to replace aesthetically after radical excision. In addition, it was necessary to perform optic canal decompression to avoid the possibility of nerve injury, especially optical disorder due to optic canal stenosis. Given these factors, we selected partial excision, even if the monostotic region was difficult to treat in cases of CMF fibrous dysplasia.

The issues with using partial excision are the possibility of recurrence and malignant change after surgery, as approximately $42 \%$ of cases experience recurrence when treated with partial excision compared with no recurrences for radical excision. In addition, $68 \%$ of cases experience recurrence when they are treated with partial excision of the Zone 4 mandibular bone. Regarding malignant changes, less than $1 \%$ of these lesions develop into osteosarcoma, and there is a $0.4 \%$ chance of malignant change, despite the rate of malignancy being 400 fold higher than in the normal population [5]-[7]. Based on these previous reports, our treatment procedure should include a long enough observation period to confirm that osseous growth has ceased. At that point, surgery should be planned if we can evaluate whether the region has stopped growing. In addition, we will conduct careful long-term observation to identify any recurrence after the surgery.

\section{Conclusion}

Fibrous dysplasia is a benign osseous disease, and radical resection is commonly recommended because of the possibility of recurrence or malignant change. However, in our department, conservative shaving has been successfully applied to the maxillofacial lesions, with positive long-term outcomes.

\section{Conflicts of Interest}

The authors declare that there are no conflicts of interest regarding the publication of this manuscript.

\section{References}

[1] Bauer, W., Albright, F. and Aub, J.C. (1930) A Case of Osteitis Fibrosa Cystica (Osteomalacia?) with Evidence of Hyperactivity of the Para-Thyroid Bodies. The Journal of Clinical Investigation, 8, 229-248. http://dx.doi.org/10.1172/JCI100262

[2] Lichtenstein, L. (1938) Polyostotic Fibrous Dysplasia. Archives of Surgery, 36, 874-898. http://dx.doi.org/10.1001/archsurg.1938.01190230153012

[3] Thoma, K.H. (1956) Differential Diagnosis of Fibrous Dysplasia and Fibro-Osseous Neoplastic Lesions of the Jaws and Their Treatment. The Chicago Journal of Oral Surgery, 14, 185-194.

[4] Chen, Y.R. and Noordhoff, M.S. (1990) Treatment of Craniomaxillofacial Fibrous Dysplasia: How Early and How Extensive? Plastic and Reconstructive Surgery, 85, 835-942. http://dx.doi.org/10.1097/00006534-199011000-00002

[5] Ruggieri, P., Sim, F.H., Bond, J.R. and Unni, K.K. (1994) Malignancies in Fibrous Dysplasia. Cancer, 73, $1411-1424$. http://dx.doi.org/10.1002/1097-0142(19940301)73:5<1411::AID-CNCR2820730516>3.0.CO;2-T

[6] Schwartz, D.Z. and Alpert, M. (1964) The Malignant Transformation of Fibrous Dysplasia. The American Journal of the Medical Sciences, 247, 1-20. http://dx.doi.org/10.1097/00000441-196401000-00001

[7] Kato, K., Hayashi, T., Tabuchi, K., Okuzumi, N., Kigasawa, H., Abe, Y., et al. (2007) Concurrent Ewing Sarcoma Family of Tumors and Fibrous Dysplasia: Possible Diagnostic Pitfall. Journal of Pediatric Hematology/Oncology, 29, 15-18. http://dx.doi.org/10.1097/MPH.0b013e31803076bb 